\title{
Synthesis and Characterization of PPV Monomer for Subsequent Electropolymerization
}

\author{
Álvaro Fontana, ${ }^{1}$ Fábio Santana dos Santos, ${ }^{1}$ Flávia Aparecida Fonseca, ${ }^{2}$ \\ Adonilson Dos Reis Freitas, ${ }^{1}$ Andersson Barison, ${ }^{2}$ and Jarem Raul Garcia ${ }^{1}$ \\ ${ }^{1}$ Department of Chemistry, State University of Ponta Grossa, Uvaranas, General Carlos Cavalcanti Avenue 4748, \\ 84030-900 Ponta Grossa, PR, Brazil \\ ${ }^{2}$ Department of Chemistry, Federal University of Parana, Polytechnic Center, Garden of the Americas, \\ Coronel Francisco Heráclito dos Santos Street 100, P.O. Box 19032, 81531-980 Curitiba, PR, Brazil
}

Correspondence should be addressed to Álvaro Fontana; alvaro.font@gmail.com

Received 6 February 2015; Revised 12 April 2015; Accepted 16 April 2015

Academic Editor: Ewa Schab-Balcerzak

Copyright (C) 2015 Álvaro Fontana et al. This is an open access article distributed under the Creative Commons Attribution License, which permits unrestricted use, distribution, and reproduction in any medium, provided the original work is properly cited.

\begin{abstract}
Organic synthesis of the monomer of poly(p-phenylenevinylene) was performed starting by the 2,5-dimethylphenol compound. An iodine atom was added to one end of the aromatic ring and then the iodine atom was substituted by a cyano group. Opposite to the cyano group was added a chain of six carbon atoms and the end of the carbon chain has an added bromine atom. The characterizations of the obtained compounds were made by FTIR, GC-MS, ${ }^{1} \mathrm{H}$, and ${ }^{13} \mathrm{C}$ NMR and showed that almost all of the proposed monomers were obtained in their totality.
\end{abstract}

\section{Introduction}

One of the ways used to change the electronic properties of conjugated polymers is to add side chain substituents, donors, and/or electron acceptors in the polymer chain, as it is known that when substituted benzenes undergo electrophilic attack, the substituent groups already present in the ring affect the rate of reaction and the attack site. The substituent groups can be divided into two classes according to their influence on the reactivity of the ring [1-4].

Those which make ring more reactive than benzene are activator groups, and those which make the ring less reactive than benzene are called deactivator groups. The activating groups on the aromatic ring influence electrophilic reactions in order to guide the attack electrophiles in a position ortho or para to the substituent of the ring, which may also be called guiding ortho-para. In other classes of substituents, the deactivator tends to direct electrophilic substitution at the meta position, so we call this groups of guiding meta. In the case of the monomer to be prepared in this study, the starting material 2,5-dimethylphenol has a hydroxyl group, and this group directs all reactions carried out in the ortho and para positions, being an activator group, or makes them more reactive aromatic ring due to partial increase of negative charges in the ortho and para positions [4].

Two effects are responsible for the orientations of the aromatic electrophilic substitutions: inductive effect and the resonance effect. The resonance effect, that is, the effect realized by hydroxyl present in the 2,5-dimethylphenol, is found by substituents which have one or more pairs of nonbonding electrons and refers to the ability to increase or decrease the stability of intermediate ion by resonance [4-7]. The substituent group can, for example, cause one of the contributions to the resonance hybrid. As for activating groups, they are those that increase the stability of the ring by injecting electrons into the aromatic ring. The effect is illustrated in Scheme 1.

By carefully choosing the deactivator or activating group or altering the side chain functionalities, one should be able to fabricate polymeric films to be applied as an active layer of electrochemical sensors, for example, humidity sensors [3].

In this paper we propose the synthesis of a derivative monomer PPV that has in its structure a cyano group and $\pi$ acceptor, connected directly to the ring, since it is known that 
Ortho position attack<smiles>CC1=C(F)[C@@H](O)C(C)C=C1</smiles>

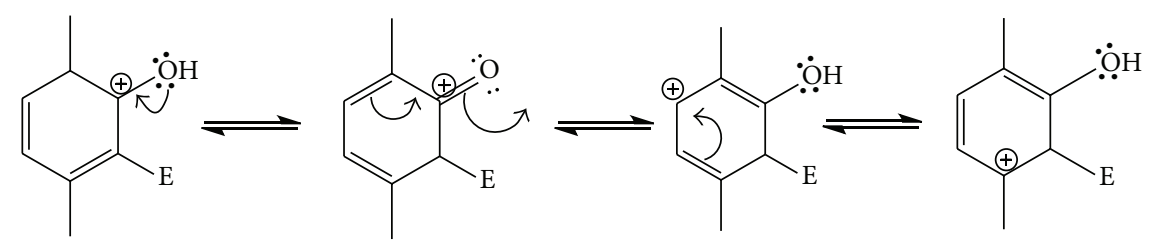

Relatively stable intermediate ion

Para position attack<smiles>CC1=CC(O)=C(C)[C+]C1F</smiles>

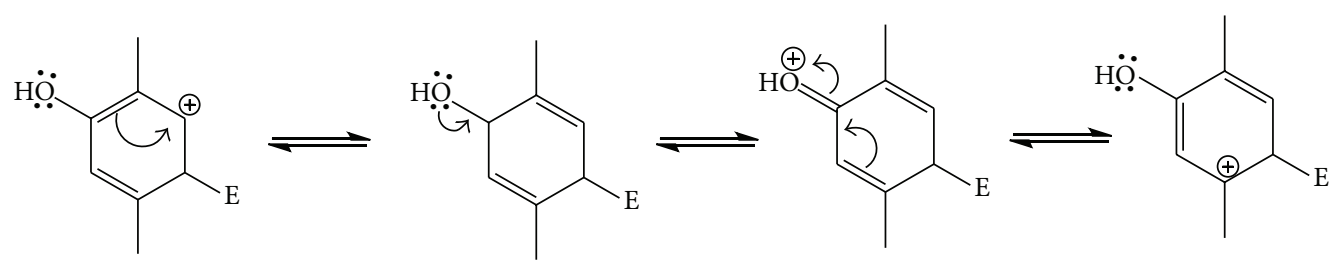

Relatively stable intermediate ion

SCHEME 1: Resonance structures of ortho and para attacks in electrophilic substitutions with activator group, where "E" can be any electrophile.<smiles>Cc1ccc(C)c(O)c1</smiles>

Scheme 2: Synthesis of 4-iodo-2,5-dimethylphenol.

this group stabilizes the HOMO and LUMO levels, being able to control their relatives positions [8]. In the para position to the cyano group we introduce a six carbon atoms chain and at the end of the carbon chain there is a bromine atom.

\section{Materials and Methods}

2.1. Synthesis of 4-Iodo-2,5-dimethylphenol. In this organic synthesis, Scheme 2, we used 0.02 moles of 2,5-dimethylphenol and equivalent amounts of sodium iodide and sodium hydroxide were dissolved in $50 \mathrm{~mL}$ of methanol present in a three-necked flask. The solution was cooled in an ice bath and sodium chloride solution until the temperature reached $0^{\circ} \mathrm{C}$ for temperature control coupled to a thermometer in one of the necked flasks. In another necked flask adapted to an addition funnel containing $37.5 \mathrm{~mL}$ of a sodium hypochlorite solution at $4 \% \mathrm{w} / \mathrm{w}$. This solution was slowly dripped into the solution contained in the flask in a way that the temperature did not exceed $4^{\circ} \mathrm{C}$.

The mixture was stirred with the aid of magnetic stirring and after the addition of all the solution from the funnel, the mixture was left under stirring for another two hours at a temperature between 0 and $2^{\circ} \mathrm{C}$ [9]. For product purification, the obtained solution was treated with $40 \mathrm{~mL}$ of an aqueous solution of sodium thiosulfate $\left(\mathrm{Na}_{2} \mathrm{~S}_{2} \mathrm{O}_{3}\right)$ to $10 \%$ and then the $\mathrm{pH}$ was adjusted to 7.0 using a $10 \%$ hydrochloric acid solution. In some cases the product was crystallized at this point and can thus be filtered. By having no crystallization occurred, $50 \mathrm{~mL}$ of chloroform was added and the phases were separated by separatory funnel. So it was added to the calcium carbonate anhydrous in the organic phase (drying agent) and the solution was then filtered and the solvent was 


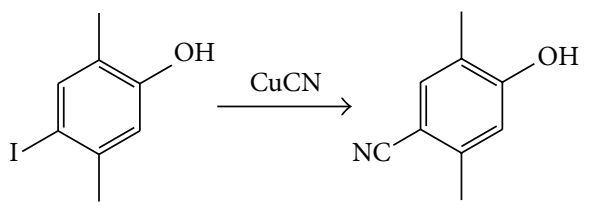

Scheme 3: Synthesis of 4-hydroxy-2,5-dimethylbenzonitrile.

subjected to fractional distillation under reduced pressure, b.p. about $40^{\circ} \mathrm{C} / 400 \mathrm{mmHg}$ [10]. The product, 4-iodo-2,5dimethylphenol, had a yield of $75 \%$ and the melting point of the crystals was approximately $90^{\circ} \mathrm{C}$.

2.2. Synthesis of 4-Hydroxy-2,5-dimethylbenzonitrile. In the synthesis of Scheme 3, 0.02 moles of 4-iodo-2,5-dimethylphenol obtained above was also employed and was dissolved in $20 \mathrm{~mL}$ of $\mathrm{N}, \mathrm{N}$-dimethylformamide (DMF) and the mixture brought to an addition funnel. An equivalent amount in moles plus $10 \%$ copper cyanide was also dissolved in $20 \mathrm{~mL}$ of DMF and added to a three-way flask $[8,9]$.

The system has been mounted in which a flask inputs received the dropping funnel; the other was connected to a condenser and the third way is closed. With the aid of magnetic stirrer and heater it started heating. With the beginning of reflux the entire solution was dripped slowly in the dropping funnel. After complete addition, the solution was refluxed continuously for another 6 hours [9]. After time of reflux, the solution was allowed to reach room temperature and was added to $40 \mathrm{~mL}$ of a saturated solution of ethylenediaminetetraacetic EDTA, which was allowed to stir for 24 hours.

After this stage, the solution was cooled down to obtain better crystals and then filtered. For purification the product was performed chemically active with an extraction solvent, where it is first dissolved in chloroform and we transferred the entire contents to a separating funnel, which underwent five washes with $5 \%$ sodium hydroxide. When obtaining an aqueous extract it was adjusted to $\mathrm{pH} 7.0$ with drops of concentrated hydrochloric acid to obtain a precipitate which is filtered and dried in a vacuum desiccator $[9,11]$. The product was obtained in a yield of $35 \%$, and its melting point was $121^{\circ} \mathrm{C}$.

2.3. Synthesis of 4-[(6-Hydroxyhexyl)oxy]-2,5-dimetilbenzonitrile. The synthesis of Scheme 4 followed the method described by Chang et al. [10], where compound was prepared by alkylation of 4-hydroxy-2,5-dimethylbenzonitrile with 6chlorohexan-1-ol. A solution of 0.01 moles of 4-hydroxy-2,5dimethylbenzonitrile, 0.015 moles of potassium hydroxide, and 0.00105 moles of tetrabutylammonium bromide in $20 \mathrm{~mL}$ of distilled water was stirred at room temperature for 15 minutes. Subsequently we slowly added 0.01 moles of 6 clorohexan-1-ol [10].

The reaction proceeded with stirring and reflux for 22 hours. After complete reaction the product was extracted with $30 \mathrm{~mL}$ of chloroform. This organic phase was washed with a sodium hydroxide solution of $10 \%$ and boiling water successively. Dry the resulting organic layer with anhydrous magnesium sulphate for 24 hours, and then we filtered and carried out a fractionated distillation of the solvent under reduced pressure, b.p. about $40^{\circ} \mathrm{C} / 400 \mathrm{mmHg}$, to give 4-[(6hydroxyhexyl)oxy]-2,5-dimethylbenzonitrile, a light brown oil $[10,12]$. From the obtained mass, the volume was calculated using the approximate density of the compound, $1.33 \mathrm{~g} \cdot \mathrm{mL}^{-1}$, and had a yield of about $30 \%$.

\subsection{Synthesis of 4-[(6-Bromohexyl)oxy]-2,5-dimetilbenzoni-} trile. For this synthesis, Scheme 5 was adapted from the hydrobromic acid's method described by [13], where the procedure was applied for the preparation of 4-[(6-bromohexyl)oxy]-2,5-dimetilbenzonitrile from 4-[(6-hydroxyhexyl)oxy]-2,5-dimetilbenzonitrile. In a $25 \mathrm{~mL}$ flask $0.50 \mathrm{~mL}$ of concentrated sulphuric acid was slowly dissolved in $0.80 \mathrm{~mL}$ of $48 \%$ hydrobromic acid under stirring and external cooling. $1.5 \mathrm{~mL}$ of 4-[(6-hydroxyhexyl)oxy]-2,5-dimetilbenzonitrile was added then portion wise we added over $0.35 \mathrm{~mL}$ of concentrated sulphuric acid [12].

The system was allowed to warm to $30^{\circ} \mathrm{C}$ for 2 hours and formed two phases. We moved the cooled reaction mixture to a separatory funnel, separated the organic phase, washed it with $20 \mathrm{~mL} 10 \%$ hydrochloric acid, $20 \mathrm{~mL}$ of distilled water, and $10 \mathrm{~mL}$ of an aqueous solution of $5 \%$ sodium hydroxide, and finally we washed it again with $20 \mathrm{~mL}$ of distilled water. The dry organic phase was extracted with anhydrous magnesium sulphate during a time of 24 hours.

With filtration of the dried product directly to a $25 \mathrm{~mL}$ flask and held fractional distillation under reduced pressure, b.p. about $40^{\circ} \mathrm{C} / 400 \mathrm{mmHg}$, the yield was approximately $85 \%$.

In addition to the techniques FTIR and NMR this reaction was characterized by GC-MS to verify the change of the hydroxyl group by bromine.

The solid obtained was dissolved in appropriated solvent at room temperature. An appropriate solution volume was injected into the chromatographer with a microsyringe. GC-MS was performed in a Shimadzu gas chromatograph coupled with a mass selective detector model QP2000A.

A $60 \mathrm{~m}$ long and $0.25 \mathrm{~mm}$ diameter SE-30 GC capillary column coated with poly(dimethyl siloxane) was used and the appropriate solution was injected at $80^{\circ} \mathrm{C}$. Column temperature was programmed to remain at $40^{\circ} \mathrm{C}$ for $6 \mathrm{~min}$ and then raised to $150^{\circ} \mathrm{C}$ at a heating rate of $10^{\circ} \mathrm{C} \mathrm{min}{ }^{-1}$. Helium was used as a carrier gas at a flow rate of $30 \mathrm{~mL} \mathrm{~min}^{-1}$.

\section{Results and Discussion}

3.1. Characterization of 4-Iodo-2,5-dimethylphenol. In the reaction described for obtaining 4-iodo-2,5-dimethylphenol, it is necessary basic medium to occur, $\mathrm{NaOH}$, because the presence of the base has the function to remove a proton from the hydroxyl group present in the compound 2,5-dimethylphenol, thereby forming an activating group ortho-para more reactive than phenol, which makes entry iodine atom in the para position favorable with respect to the hydroxyl group. As to attack of the electrophilic compound, it is generated in situ in the reaction medium by the reaction of sodium iodide 
<smiles>Cc1cc(C#N)c(C)cc1O</smiles>

Scheme 4: Synthesis of 4-[(6-hydroxyhexyl)oxy]-2,5-dimetilbenzonitrile.<smiles>Cc1cc(OCCCCCCO[SnH2]C2CC2)c(C)cc1C#N</smiles>

SCHEME 5: Synthesis of 4-[(6-bromohexyl)oxy]-2,5-dimetilbenzonitrile.

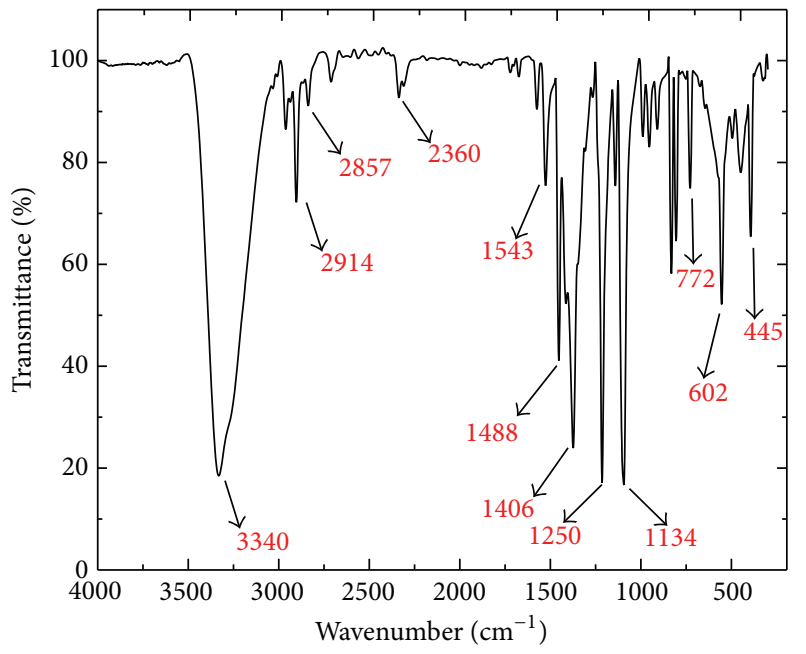

FIGURE 1: FTIR spectrum of 4-iodo-2,5-dimethylphenol.

with sodium hypochlorite which causes the $3 \mathrm{I}^{-} / \mathrm{I}_{3}{ }^{-}$complex to remain in its oxidized form, $\mathrm{I}_{3}{ }^{-}$.

To precipitate the crystals, the $\mathrm{pH}$ was adjusted to 7 for the product to acquire the characteristic of the organic salt and thus lose the water solubility. We carried out measurement of the melting point and this was $90^{\circ} \mathrm{C}$, while the theoretical melting point of this compound is between 94 and $95^{\circ} \mathrm{C}$. Compared to the melting point of 2,5-dimethylphenol, $75^{\circ} \mathrm{C}$, it appears that the increase in temperature recorded is consistent, given that the addition of an iodine atom increases the molecular weight of the compound thereby increasing its melting point.

The compound was characterized by infrared spectroscopy, FTIR, and nuclear magnetic resonance ${ }^{1} \mathrm{H}$ NMR, and such characterizations are shown in Figures 1 and 2, respectively.

In Table 1 some major bands found in the infrared spectrum obtained in $\mathrm{KBr}$ tablet are shown.

The characterization by ${ }^{1} \mathrm{H}$ NMR to ascertain main reason is that the connection of the ring formed with iodine is carried out in carbon position to the radical present in the phenol ring.

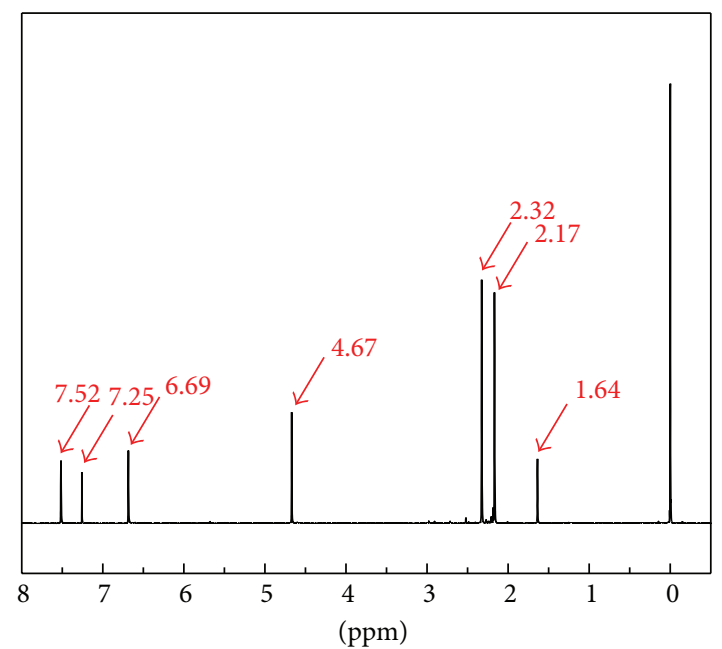

FIGURE 2: ${ }^{1} \mathrm{H}$ NMR spectrum of 4-iodo-2,5-dimethylphenol.

TABLE 1: Major bands found in the FTIR spectrum of 4-iodo-2,5dimethylphenol.

\begin{tabular}{lcc}
\hline Chemical bond & Stretch & Absorption band $\left(\mathrm{cm}^{-1}\right)$ \\
\hline O-H & Axial deformation & 3340 \\
C-H Csp ${ }^{3}$ methyl & Axial deformation & $2914-2857$ \\
C=C aromatic ring & Axial deformation & 1543,1406 and 1250 \\
C-O & Axial deformation & 1134 \\
C-I & Vibration & 602 \\
\hline
\end{tabular}

The ${ }^{1} \mathrm{H}$ NMR spectrum of Figure 2 was obtained in $\mathrm{CDCl}_{3}$ solvent, peak at $7.25 \mathrm{ppm}$. The peaks found in $\delta \sim$ $4.67 \mathrm{ppm}$ and $\delta \sim 1.63 \mathrm{ppm}$ can be hydrogen from hydroxyl group and water dissolved in chloroform, respectively, in the sample, because in solvent we used traces of water that may be contaminating the sample show peaks in these values [13, 14]. Another possibility is that the hydrogen atom behavior of hydroxyl phenols resembles the hydrogen atom of the hydroxyl alcohols. The corresponding signal is usually a sharp singlet (fast change without coupling), and the region that appears depends on the compound concentration, of 


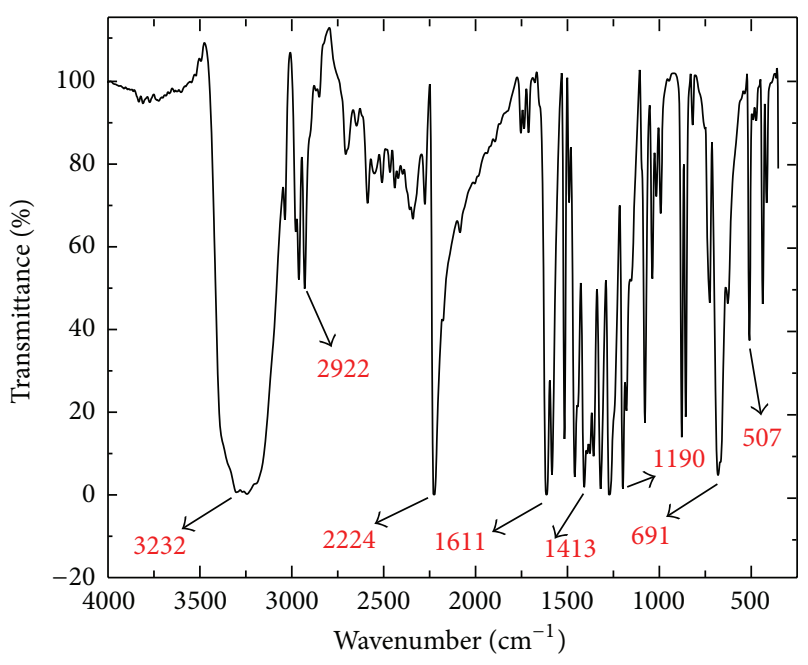

FIGURE 3: FTIR spectrum of 4-hydroxy-2,5-dimethylbenzonitrile.

the solvent and temperature, being generally in the left $(\delta \sim$ 7.5 to $\delta \sim 4.0 \mathrm{ppm}$ ) of hydrogen atom sign of hydroxyl of alcohol. Signals at 6.69 and $7.52 \mathrm{ppm}$ correspond to protons of aromatic ring and signals at 2.32 and $2.17 \mathrm{ppm}$ correspond to methyls groups to the aromatic ring [15].

The result showed that the product obtained was really the 4-iodo-2,5-dimethylphenol. The yield of synthesis was about $70 \%$. One possible alternative for increasing the yield of this reaction was dripped sodium hypochlorite more slowly to the reaction mixture or to control the temperature so that it does not exceed $2^{\circ} \mathrm{C}[16]$.

\subsection{Characterization of 4-Hydroxy-2,5-dimethylbenzonitrile.} The inclusion of the cyanide group, $\pi$-acceptor group of electrons, stabilizes energy levels HOMO and LUMO by changing the electronic distribution of the molecule. But the entry of cyanide group in the aromatic ring does not occur easily as the halogens. Therefore it was necessary to have a good leaving group in the ring for the later entrance of the cyanide group. Then first iodine atom was added in 2,5dimethylphenol compound, being a good leaving group, for later reaction with cyanide group.

The theoretical melting point of this compound is $110^{\circ} \mathrm{C}$. The melting point of the compound is consistent when comparing it with the 2,5-dimethylphenol, $75^{\circ} \mathrm{C}$, and the 4iodo-2,5-dimethylphenol, $90^{\circ} \mathrm{C}$, since the addition of a $\mathrm{CN}$ group increases the number of hydrogen bonds by increasing the intermolecular force system which causes the melting point to be also higher. To verify the formation of $\mathrm{CN}-\mathrm{C}$ coupling was performed and FTIR spectroscopy, obtaining the spectrum of Figure 3.

The assignment of the bands observed in this spectrum can follow the same system used in the allocation of spectrum bands of 4-hydroxy-2,5-dimethylbenzonitrile. However one must consider the disappearance of the band at $602 \mathrm{~cm}^{-1}$ shown in Figure 1 related to the axial vibration of the C-I bond and the appearance of the band at $2224 \mathrm{~cm}^{-1}$ in Figure 3 which can be attributed to the presence of the $\mathrm{CN}$ group.
TABLE 2: Major bands found in the FTIR spectrum of 4-hydroxy2,5-dimethylbenzonitrile.

\begin{tabular}{lcc}
\hline Chemical bond & Stretch & Absorption band $\left(\mathrm{cm}^{-1}\right)$ \\
\hline O-H & Axial deformation & 3332 \\
C-H Csp ${ }^{3}$ methyl & Axial deformation & $2922-2857$ \\
CN & Axial deformation & 2224 \\
C=C aromatic ring & Axial deformation & 1543,1406 and 1250 \\
C-O & Axial deformation & 1134 \\
\hline
\end{tabular}

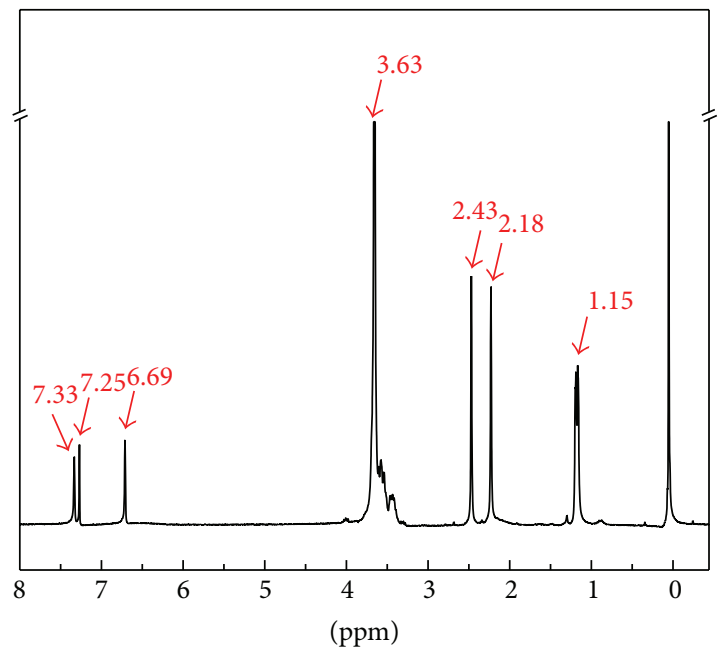

FIGURE 4: ${ }^{1} \mathrm{H}$ NMR spectrum of 4-hydroxy-2,5-dimethylbenzonitrile.

In Table 2 some major bands found in the infrared spectrum obtained in $\mathrm{KBr}$ tablet are shown.

The ${ }^{1} \mathrm{H}$ NMR spectrum in Figure 4 was obtained using $\mathrm{CDCl}_{3}$ solvent, peak at $7.25 \mathrm{ppm}$, and showed other peaks.

In the spectrum of Figure 4 a peak was also observed at $3.63 \mathrm{ppm}$ which can be hydrogen of hydroxyl group and at $1.15 \mathrm{ppm}$ which can indicate that the sample is possibly contaminated with traces of water, while making the purification process as described in [17]. Shifting the two signals seen in Figure 4 (3.63 and $1.15 \mathrm{ppm}$ ) in relation to Figure 3 may be attributed to the electronic effects of the $\mathrm{CN}$ group in the molecule $[1,4,9,11]$.

Peaks found in the ${ }^{1} \mathrm{H}$ NMR showed the chemical shifts expected for the hydrogen atoms present in the molecule 4hydroxy-2,5-dimethylbenzonitrile. With the results obtained by the characterizations, we confirmed the formation of the expected product in this organic synthesis.

3.3. Characterization of 4-[(6-Hydroxyhexyl)oxy]-2,5-dimethylbenzonitrile. This reaction aims to form a compound containing six carbon atoms between the aromatic ring and an $\mathrm{OH}$ grouping at end of chain. This structure is interesting to act as a strong flexible drive to the proton conduction function in the compound after the polymerization [14].

According to the spectrum shown in Figure 5, the bands found correspond to the compound 4-[(6-hydroxyhexyl)oxy]-2,5-dimetilbenzonitrile. It was confirmed that 


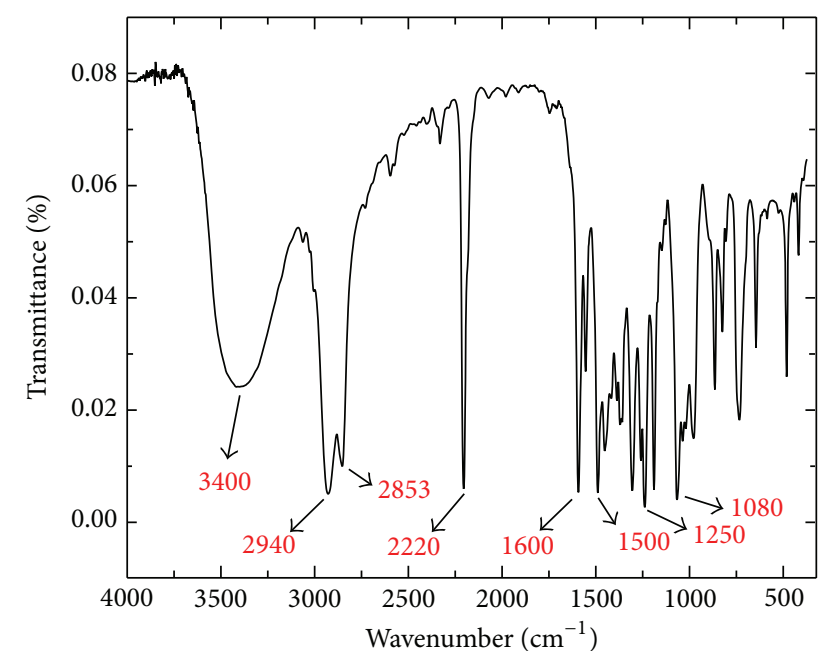

FIGURE 5: FTIR spectrum of 4-[(6-hydroxyhexyl)oxy]-2,5-dimethylbenzonitrile.

TABLE 3: Major bands found in the spectrum FTIR of 4-[(6-hydroxyhexyl)oxy]-2,5-dimethylbenzonitrile.

\begin{tabular}{|c|c|c|}
\hline Chemical bond & Stretch & $\begin{array}{c}\text { Absorption band } \\
\left(\mathrm{cm}^{-1}\right)\end{array}$ \\
\hline $\mathrm{O}-\mathrm{H}$ & Axial deformation & 3400 \\
\hline C-H Csp ${ }^{3}$ methyl & Axial deformation & 2940 \\
\hline $\mathrm{C}-\mathrm{H} \mathrm{Csp}^{3}\left(-\mathrm{CH}_{2^{-}}\right)$ & $\begin{array}{l}\text { Axial deformation } \\
\text { (asymmetric and } \\
\text { symmetric) }\end{array}$ & 2853 \\
\hline $\mathrm{CN}$ & Axial deformation & 2220 \\
\hline $\mathrm{C}=\mathrm{C}$ aromatic ring & Axial deformation & 1600,1500 \\
\hline $\begin{array}{l}\mathrm{C}-\mathrm{O} \\
\text { (alkyl-aryl-ether) }\end{array}$ & $\begin{array}{l}\text { Axial deformation } \\
\text { (asymmetric and } \\
\text { symmetric) }\end{array}$ & 1250 \\
\hline C-O alcohol & Axial deformation & 1080 \\
\hline
\end{tabular}

the existence of the spectrum CN group of methyl bound to the aromatic ring of the side chain methylene present in the compound and that the presence of the alcoholic, $\mathrm{OH}$ group and ether was attached to the aromatic ring.

The values of the bands of each connection are shown in Table 3. To confirm obtaining the compound, ${ }^{1} \mathrm{H}$ NMR analyses, Figure 6, were performed in order to compare product formation by the existence of a $\mathrm{CN}$ group bound to the aromatic ring and the existence of the chain side containing six carbon atoms having the $\mathrm{OH}$ group at the end of the carbon chain.

The spectrum of Figure 6 was obtained in $\mathrm{CDCl}_{3}$ solvent, peak at 7.25, and shows two singlets relating to the chemical shift region of hydrogen atom attached to the aromatic ring in 7.30 and $6.65 \mathrm{ppm}$. These peaks indicate that only two singlets of the aromatic ring carbons are not substituted and hydrogen atoms are not close to each other. The region between the peaks of 1.45 and $1.82 \mathrm{ppm}$ are indicative of protons belonging to the side chain. The peak in $3.97 \mathrm{ppm}$ can be traces of water

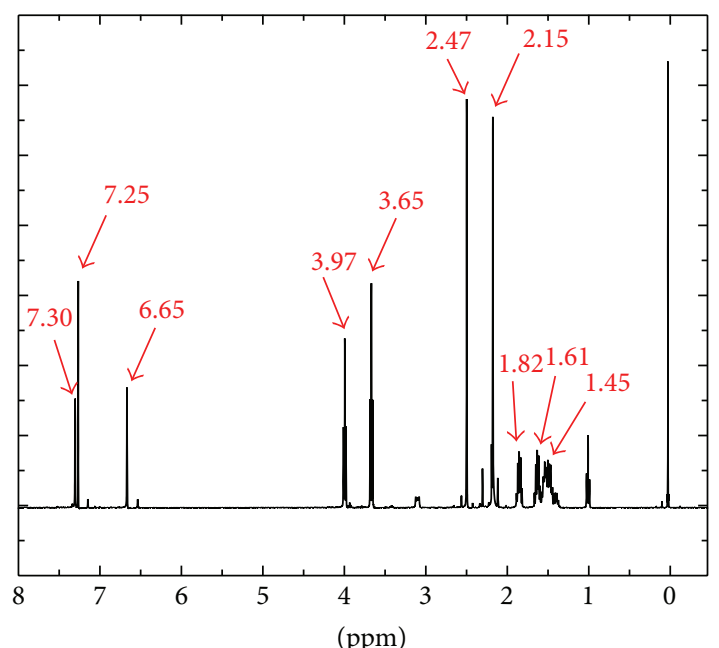

Figure 6: ${ }^{1} \mathrm{H}$ NMR Spectrum of 4-[(6-hydroxyhexyl)oxy]-2,5dimethylbenzonitrile.

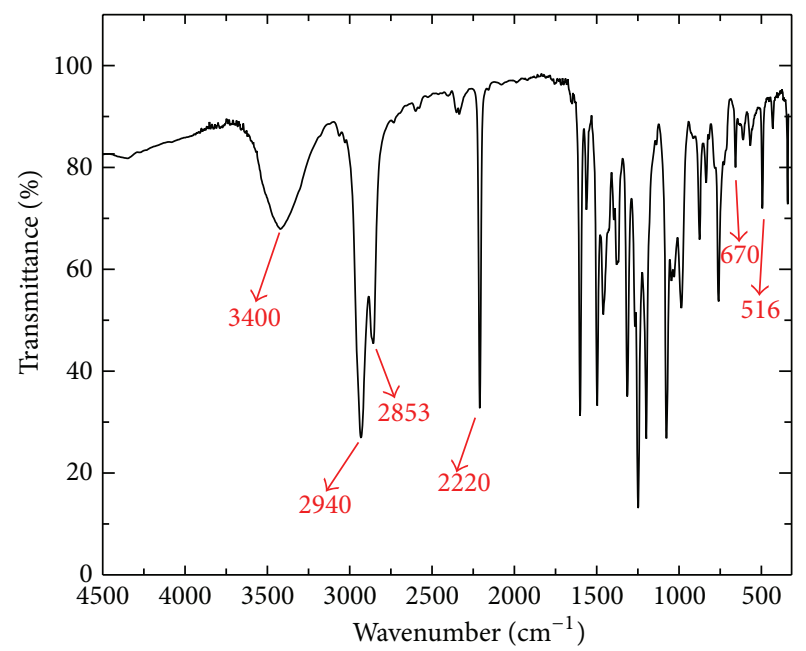

FIGURE 7: FTIR spectrum of 4-[(6-bromohexyl)oxy]-2,5-dimethylbenzonitrile.

and the peak in $3.65 \mathrm{ppm}$ is signal with respect to proton linked to ether group in molecule.

It can be said then that the aromatic ring is connected to not only the methyl group in positions 2 and 5 because of the signs in 2.47 and $2.15 \mathrm{ppm}$, but also the cyano group and the side chain composed of 6 carbon atoms attached to the aromatic ring and a hydroxyl group at the end of carbon chain.

3.4. Characterization of 4-[(6-Bromohexyl)oxy]-2,5-dymethylbenzonitrile. According to Figure 7, it is not possible to say with certainty whether there was formation of compound 4-[(6-bromohexyl)oxy]-2,5-dimethylbenzonitrile, since the difference between the this compound and 4-[(6-hydroxyhexyl)oxy]-2,5-dimethylbenzonitrile is the carbon-bromine bond in the end of the side chain where the hydroxyl group was replaced by a bromine atom. The bromine compound 


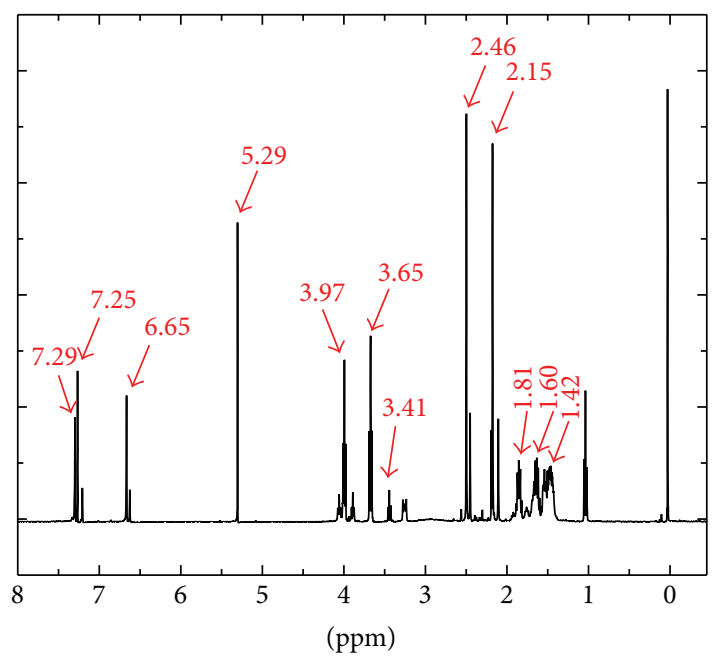

FIGURE $8:{ }^{1}$ HNMR spectrum of 4-[(6-bromohexyl)oxy]-2,5-dimethylbenzonitrile.

absorbs in the regions of 690 and $515 \mathrm{~cm}^{-1}$ and in Figure 7 there are two very close bands with these theoretical values for the bromination reaction of halogenated organic compounds signs but they have lower intensity than expected.

It is also possible to see that there was a decrease of the band at $3470 \mathrm{~cm}^{-1}$ when compared to the spectrum of Figure 5 which corresponds to compound 4-[(6-hydroxyhexyl)oxy]-2,5-dimethylbenzonitrile, in that region, indicating the presence of hydroxyl group at the end of the chain. It might be supposed that there is substitution of the hydroxyl group by a bromine atom at the end of the side chain; however, bands corresponding to bromine absorption are small. To confirm the structure of the compound ${ }^{1} \mathrm{H}$ NMR analysis was done as it can be seen in Figure 8 .

Figure 8 shows that the ${ }^{1} \mathrm{H}$ NMR spectrum of the compound 4-[(6-bromohexyl)oxy]-2,5-dimethylbenzonitrile was obtained in $\mathrm{CDCl}_{3}$ solvent, which is the difference in molecular structure compared to the compound 4-[(6-hydroxyhexyl)oxy]-2,5-dimethylbenzonitrile of Figure 6, which is bromine-carbon bond at one end of the side chain in place of the hydroxyl group.

In Figure 8 a signal appears at $3.65 \mathrm{ppm}$; it is signal with respect to proton linked to ether group in molecule and has a triplet at 3.41, but with lower intensity. The region between the peaks of 1.42 and $1.81 \mathrm{ppm}$ is indicative of protons belonging to the side chain. The remainder of the observed signals is quite similar for both compounds. To confirm if they were actually replacing the hydroxyl group by a bromine atom in the compound 4-[(6-hydroxyhexyl)oxy]2,5-dimetilbenzonitrile ${ }^{13} \mathrm{C}$ NMR analysis was made as shown in Figure 9.

The chemical shifts of the signal expected for the carbonbromine bond are at $33.80 \mathrm{ppm}$, whereas carbon-hydroxyl bond happens at $62.70 \mathrm{ppm}$. There is a chemical shift signal at $32.79 \mathrm{ppm}$ and a small signal at $33.60 \mathrm{ppm}$. These values could be evidence that the compound 4-[(6-bromohexyl)oxy]-2,5dimethylbenzonitrile was obtained but in the same spectrum

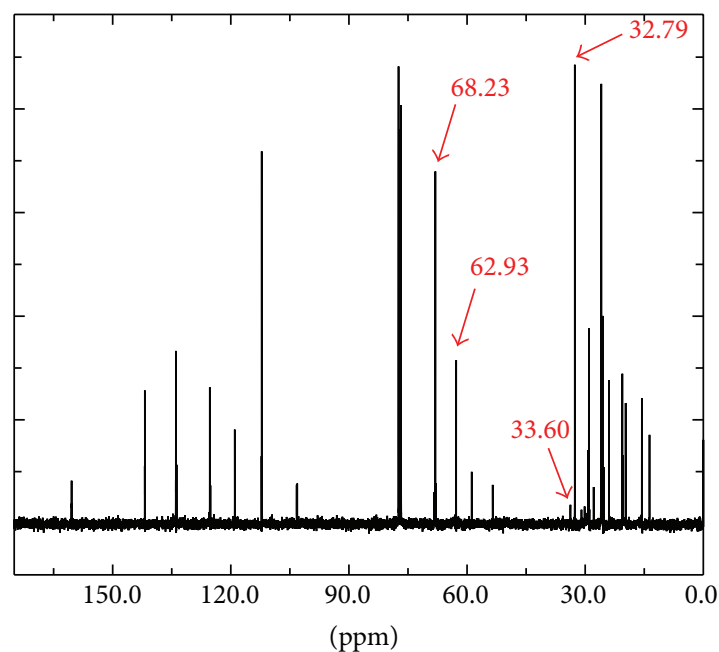

FIGURE 9: ${ }^{13} \mathrm{C}$ NMR spectrum of 4-[(6-bromohexyl)oxy]-2,5dimethylbenzonitrile.

there is a signal at $62.93 \mathrm{ppm}$. These values lead us to believe that the compound was obtained but is present in a mixture with the 4-[(6-hydroxyhexyl)oxy]-2,5-dimethylbenzonitrile compound.

In Figure 10 the multiple peaks in the GC-MS chromatogram reveal that several products are formed during a synthesis process. Freitas et al. [17] used this technique in available degradation process of polychloroprene. He measured the appearing new peaks in CG-MS as functioning as degradation reaction. Curti et al. [18] study of similar system arrived at same conclusion. This technique permits availing the appearing or disappearing, such as the identification of substance in a chemical process. In this sense, the GC-MS was used. In this spectrum it is possible to see the presence of duplicate signal of the molecular ion bromine isotope in $m / z=308.98$ and the peak signal based on $m / z=147$ which is expected to sign the most stable fragment, $\mathrm{C}_{9} \mathrm{H}_{8} \mathrm{ON}$.

Due to large extension of the target molecule an enormous fragment was waited in chromatogram. Peak with $m / z=310$ was found, $\mathrm{C}_{15} \mathrm{H}_{20} \mathrm{BrON}$. These peaks found in the chromatogram are according to data from NMR and FTIR spectroscopy and this permits us to conclude that target molecule was obtained.

\section{Conclusion}

In this work organic synthesis of the monomers precursors of class of the poly-p-phenylenevinylene for possible later electropolymerization was made, whose infrared spectra are ${ }^{1} \mathrm{H}$ and ${ }^{13} \mathrm{C}$. NMR data confirmed obtaining the compounds, 4-iodo-2,5-dimethylphenol, 4-hydroxy-2,5-dimethylbenzonitrile, and 4-[(6-hydroxyhexyl)oxy]-2,5-dimethylbenzonitrile, wherein the compound 4-[(6-bromohexyl)oxy]-2,5dimethylbenzoni-trile was obtained but contains impurities in its structure, or associated to a mixture of compounds; this result is also confirmed by Figure 10, GC-MS technique, and Figure $9,{ }^{13} \mathrm{C}$ NMR spectrum. 


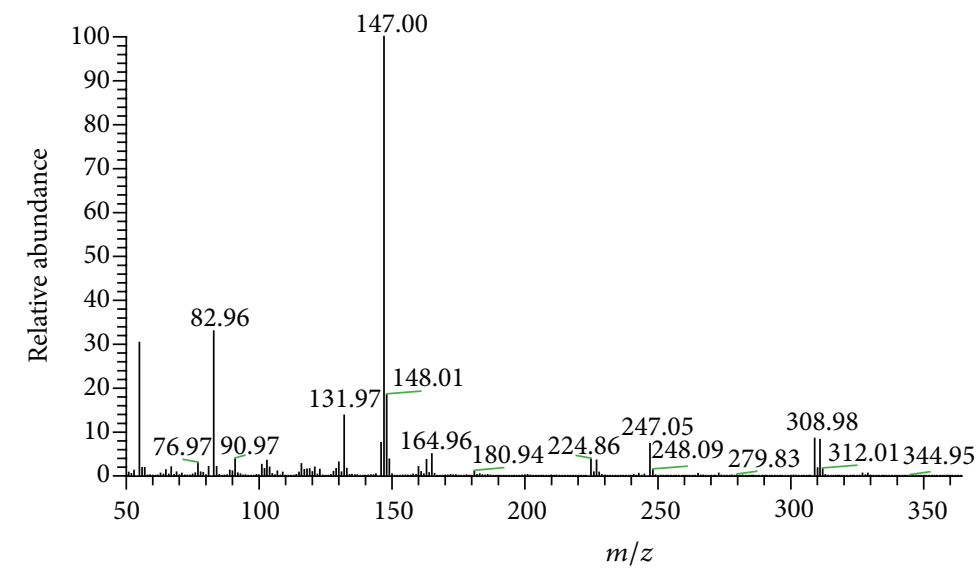

FIGURE 10: Mass spectra of 4-[(6-bromohexyl)oxy]-2,5-dimethylbenzonitrile.

\section{Conflict of Interests}

The authors declare that there is no conflict of interests regarding the publication of this paper.

\section{References}

[1] L. Akcelrud, "Electroluminescent polymers," Progress in Polymer Science, vol. 28, no. 6, pp. 875-962, 2003.

[2] K. Norrman, N. B. Larsen, and F. C. Krebs, "Lifetimes of organic photovoltaics: combining chemical and physical characterisation techniques to study degradation mechanisms," Solar Energy Materials and Solar Cells, vol. 90, no. 17, pp. 2793-2814, 2006.

[3] N. Grossiord, J. M. Kroon, R. Andriessen, and P. W. M. Blom, "Degradation mechanisms in organic photovoltaic devices," Organic Electronics: Physics, Materials, Applications, vol. 13, no. 3, pp. 432-456, 2012.

[4] T. W. G. Solomons and C. B. Fryhle, Organic Chemistry, LTC, Rio de Janeiro, Brasil, 10th edition, 2012.

[5] S. Yoon, H.-J. Choi, J.-K. Yang, and H.-H. Park, "Comparative study between poly(p-phenylenevinylene) (PPV) and PPV/ $\mathrm{SiO}_{2}$ nano-composite for interface with aluminum electrode," Applied Surface Science, vol. 237, no. 1-4, pp. 450-455, 2004.

[6] J. F. Lee, S. L. C. Hsu, P. I. Lee, H. Y. Chuang, J. S. Chen, and W. Y. Chou, "A new narrow bandgap polyfluorene copolymer containing 2,6-bis-(3-hexyl-thiophen-2-yl)-anthraquinone unit for solar cell applications," Solar Energy Materials \& Solar Cells, vol. 96, no. 1, pp. 218-225, 2012.

[7] J. L. Brédas and A. J. Heeger, "Influence of donor and acceptor substituents on the electronic characteristics of poly(paraphenylene vinylene) and poly(paraphenylene)," Chemical Physics Letters, vol. 217, pp. 507-512, 1994.

[8] H. Firouzabadi, N. Iranpoor, and M. Jafarpour, "A simple, efficient, and highly selective method for the iodination of alcohols using $\mathrm{ZrCl}_{4} / \mathrm{NaI}$," Tetrahedron Letters, vol. 45, no. 40, pp. 7451-7454, 2004.

[9] H. Ryu, L. R. Subramanian, and M. Hanack, "Photo- and electroluminescent properties of cyano-substituted styryl derivatives and synthesis of CN-PPV model compounds containing an alkoxy spacer for OLEDs," Tetrahedron, vol. 62, no. 26, pp. 6236-6247, 2006.
[10] H.-T. Chang, H.-T. Lee, and M.-Y. Yeh, "Synthesis and characterization of the soluble luminescent poly[2-decyloxy-5- $\left(4^{\prime}\right.$ ethoxyphenyl)-1,4-phenylenevinylene]," Polymer Bulletin, vol. 57, no. 6, pp. 921-932, 2006.

[11] M. R. Pinto, B. Hu, F. E. Karasz, and L. Akcelrud, "Lightemitting copolymers of cyano-containing PPV-based chromophores and a flexible spacer," Polymer, vol. 41, no. 7, pp. 26032611, 2000

[12] T. Raju, K. Kulangiappar, M. Anbu Kulandainathan, and A. Muthukumaran, "A simple and regioselective $\alpha$-bromination of alkyl aromatic compounds by two-phase electrolysis," Tetrahedron Letters, vol. 46, no. 41, pp. 7047-7050, 2005.

[13] B. G. Soares, N. A. Souza, and D. X. Pires, Química OrgânicaTeoria e Técnica de Preparação, Purificação e Identificação de Compostos Orgânicos, Guanabara S.A., Rio de Janeiro, Brazil, 1st edition, 1988.

[14] H. Wendt, M. Linardi, and E. M. Aricó, "Células a Combustível de Baixa Potência para Aplicações Estacionárias," Química Nova, vol. 3, pp. 470-476, 2002.

[15] R. M. Silverstein, G. C. Bassler, and T. C. Morrill, Spectrometric Identification of Organic Componds, John Wiley \& Sons, Singapore, 5th edition, 1991.

[16] F. Wudl and S. Shi, "Synthesis and characterization of a watersoluble poly(p-phenylenevinylene) derivative," Macromolecules, vol. 23, no. 8, pp. 2119-2124, 1990.

[17] A. R. Freitas, G. J. Vidotti, A. F. Rubira, and E. C. Muniz, "Polychloroprene degradation by a Photo-Fenton process," Polymer Degradation and Stability, vol. 87, no. 3, pp. 425-432, 2005.

[18] P. S. Curti, G. J. Vidotti, A. F. Rubira, and E. C. Muniz, "Some kinetic parameters of the degradation of natural rubber induced by chloranil and iron (III) chloride, in solution," Polymer Degradation and Stability, vol. 79, no. 2, pp. 325-331, 2003. 

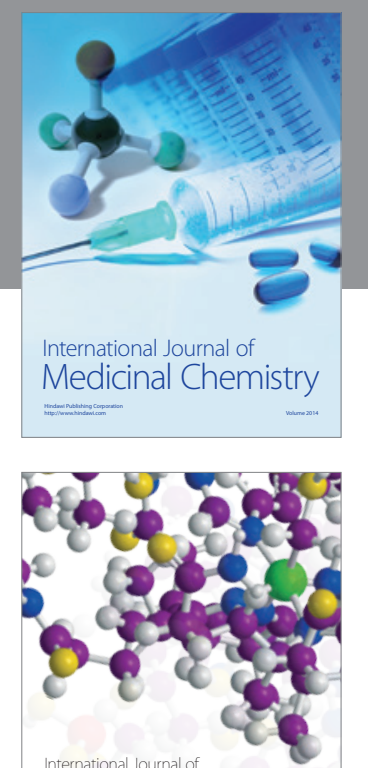

\section{Carbohydrate} Chemistry

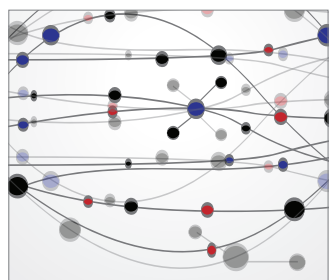

The Scientific World Journal
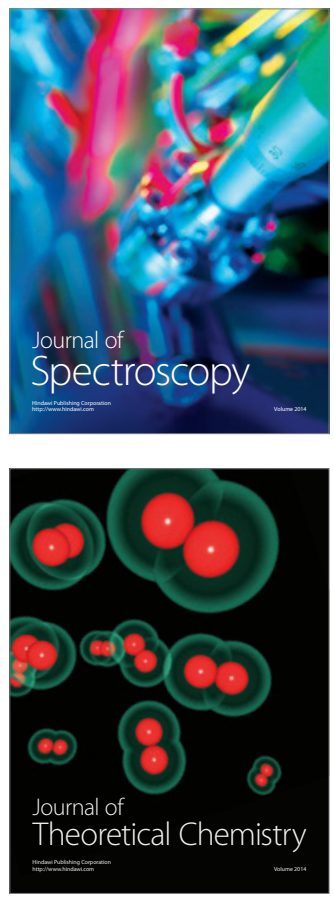
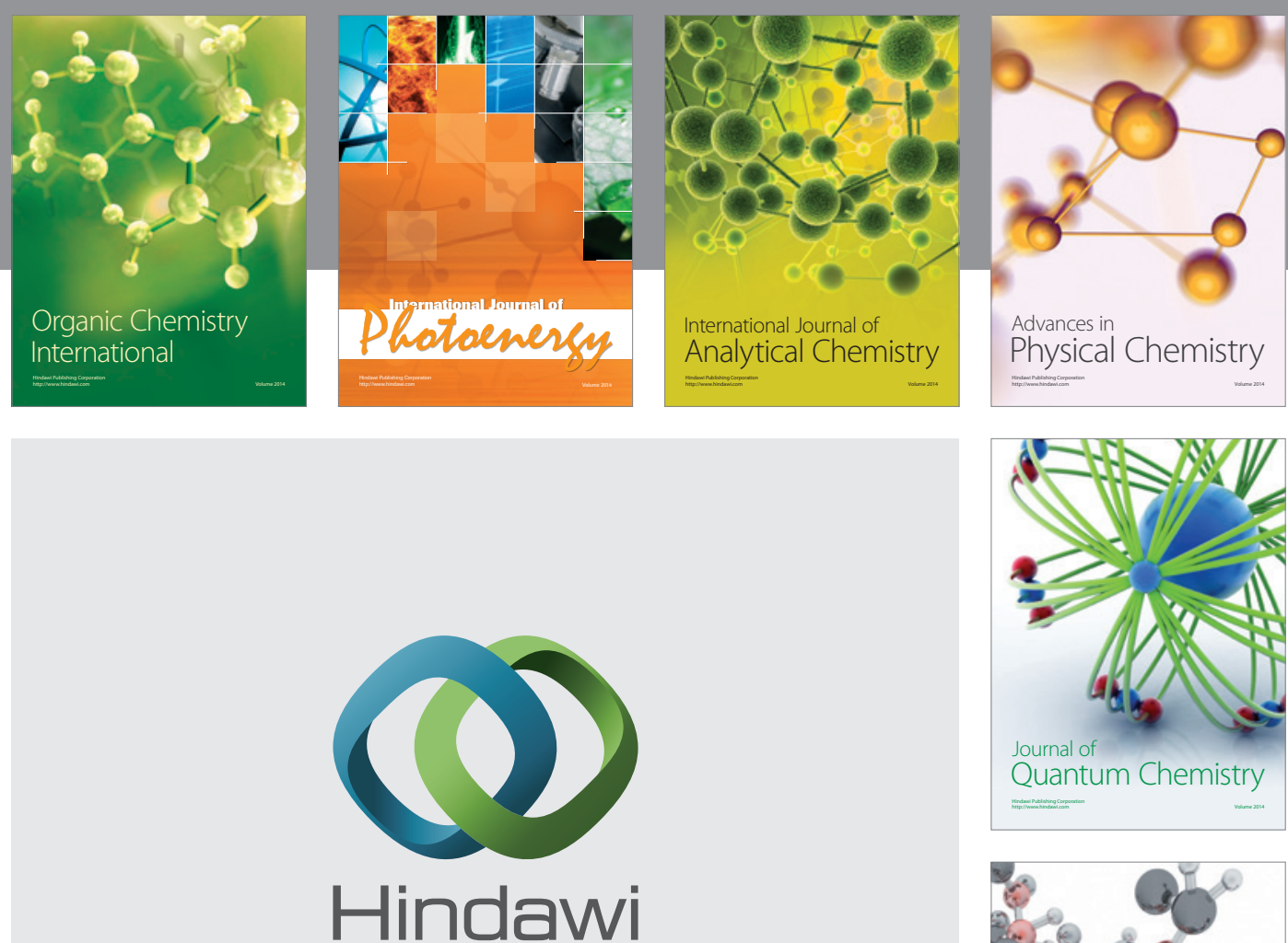

Submit your manuscripts at

http://www.hindawi.com

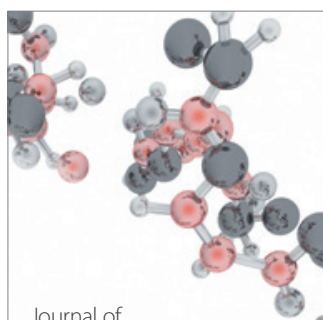

Analytical Methods

in Chemistry

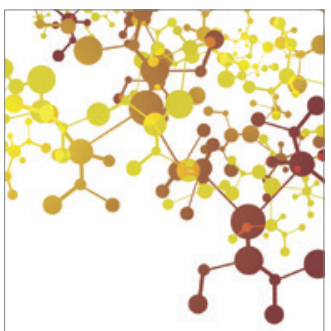

Journal of

Applied Chemistry

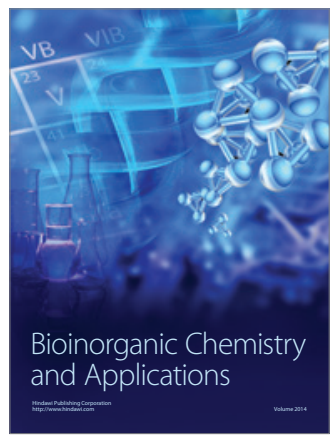

Inorganic Chemistry
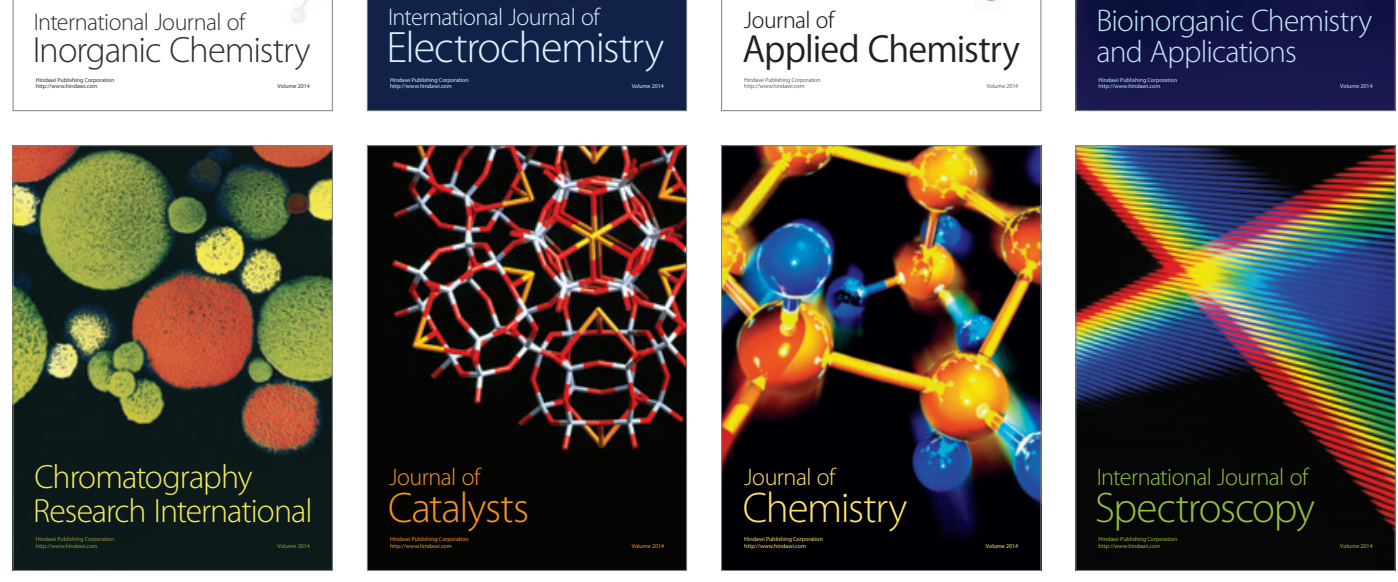